\title{
Rethinking the Human Centred Approach to Animal-Computer Interaction
}

\author{
Chloe Kliman-Silver \\ Northumbria University \\ Newcastle, UK \\ chloe.kliman-silver@northumbria.ac.uk
}

\begin{abstract}
While the field of Animal-Computer Interaction is an emerging one, the main focus has still been on humans. $\mathrm{ACl}$ research often examines ways that giving animals technology can improve some aspect of a human's life without considering the needs of the animals. A strikingly parallel problem has arisen in $\mathrm{HCl}$ as well - what does participatory design look like when working with the voiceless. In my research, using a dog's connection to its owner as a starting point, I plan to utilise the findings from past $\mathrm{HCl}$ work while working with the dogs to design a technology that they actually would want to use.
\end{abstract}

Animal-computer interaction, Human-computer interaction, Participatory design.

\section{INTRODUCTION}

Animal Computer Interaction $(\mathrm{ACl})$, a sub-field of $\mathrm{HCl}$, is described by Mancini in her seminal 2011 manifesto on $\mathrm{ACl}$ as seeking to understand the "interaction between animals and computing technology within the contexts in which the animals habitually live, are active and socialise with members of the same or other species, including humans"(Mancini, C., 2011). She suggests that the discipline can be used to improve the quality of animal lives, support animals in whatever job they do, or foster inter-species relationships (including with humans). The latter, deepening the understanding of how technology can impact the relationship between humans and animals, is the focus of my $\mathrm{PhD}$ research. Just as $\mathrm{HCl}$ seeks to understand how humans interact with technology and the resulting effects, $\mathrm{ACl}$ seeks to understand the same, but with animals.

The proliferation of cheap interactive technology and apps has resulted in a boom in technology 'designed for' dogs. This tends to come in two forms - technology for working dogs and for pets. Technology has assisted the connection between working dogs and humans, especially for those dogs working as guide dogs or assistance dogs (Hirskyj-Douglas, I., et al., 2018) (Jackson, M.M., et al., 2013). In addition to working dogs, the other current main area of technology for dogs is aimed towards pet owners. Numerous products now exist that can monitor a dog's health, behaviour, or activity through GPS monitors, fitness trackers, or video cameras (Hall, L., McDonald, S. and Young,
S., 2018) (Paasovaara,S., et al., 2011). Some of these technologies claim to strengthen the humananimal bond by allowing humans to understand more about their pets and their pets' activities when the humans are not there (Paasovaara, S., et al., 2011). Fundamentally however, in both of these cases, dogs are interacting with technology, but they are doing it for the human's benefit.

Technology for dogs remains very human-centred. As a result, some current $\mathrm{ACl}$ research - "seems to express anthropocentric concerns to ultimately address human needs... interspecies communication barriers and power inequalities make it easier for anthropocentric interests to prevail and for technology to become exploitative" (Mancini, C., Lawson, S., and Juhlin, O., 2017). While humans and animals can be very closely intertwined (either for companionship, health, or work), ACl research should not forget the animal users of their technology in order to cater towards human needs. There is therefore a small but growing movement in the $\mathrm{ACl}$ community to focus on the welfare of the animal and what the animal is getting out of the technology; simply focusing on what the human needs out of the interaction isn't enough (Mancini, C., Lawson, S., and Juhlin, O., 2017).

Technology designed purely for the enjoyment of dogs (or other animals) themselves largely only exists in the speculative sense. In a provocative 2016 article in the ACM Interactions magazine, Lawson et al discuss possible ideas that would allow dogs to interact with technology due to their own self-interests (Lawson, S., et al., 2015). Two suggestions were assuming the dog wants to know 
when its owner is coming home: first, it could use a pseudo "Find Your Friends" app; second, a "dogonly" social network could use access methods that only work if the user is a dog (smell-based entry, for example) to prevent human entry. This PhD research is motivated by some of the provocations in this article - specifically that animal-centred (rather than human-centred) ACl should finally address actually what animals want and need.

\section{STATEMENT OF THESIS}

In $\mathrm{HCl}$, a growing concern is of user empowerment: is technology designed with the users in mind? Is technology helping the users, and do the users have any kind of say in the design process and the experiments? In a 2019 article in ACM Interactions, Bannon et. al discusses how current participatory design is flawed - the user has become less integrated into the design process from the beginning, and once important ideas of conflict and power have been ignored. For groups with little to no power, the user will often have even less voice in the process; Iverson et. al offer up a solution for participatory design that allows the users to be the main conductor of the design process.

By focusing on designing technology with the purpose of giving dogs information about their world, I aim to refocus $\mathrm{ACl}$ and break the classic human-centred approach to the discipline. Importantly, the information the dogs are given must be information that they want to receive, and they must be allowed to react to this information as they see fit. Consequently, I want to design technology that dogs will pay attention to because it gives them knowledge about the world around them - including themselves, their owners, and other dogs. In order to achieve this overarching question, I will:

- Design and build technology for dogs to engage with in real-life situations.

- Build this technology so dogs are stakeholders in the design, with the intention that they will want to use it.

- Deepen an understanding of what it means to have dogs be stakeholders, recognizing among other aspects, welfare considerations when giving dogs new information.

- Deepen an understanding of what it means to have dogs be stakeholders, recognizing among other aspects, welfare considerations when giving dogs new information.

\section{RESEARCH APPROACH AND METHODS}

The research will comprise of a sequence of studies that each involve the design, development and evaluation of a piece of interactive technology for domestic dogs. The owners will be filling in surveys and participating in interviews, while the dogs will be interacting (or not) with the equipment. Since dogs are co-stakeholders, if a dog refuses to participate, this can be taken as a sign that the technology needs improving.

\subsection{Phase 1}

Inspired by para-psychologist Richard Sheldrake's claims that dogs, dogs want to know (and often do know) when their owners are coming home, the first phase examines what dogs do when their owners are not home (Sheldrake, R. 2011\}. Furthermore, this phase examines whether the dogs care when their owners come home.

For the experiment, both the dog and the owner in the dyad will carry around phones with customised android apps. The dog version pulls data from various sensors (including a gyroscope and an accelerometer) and location; the dog will carry the phone around on a customised harness. The human version will only pull location data. All data will be stored in the cloud.

In this experiment, I am defining "caring" as behaving differently when the owner comes home. I am also asking the owners to change up their schedule slightly - dogs can become accustomed to routine and expect their owner home at a certain time.

However, the overlying question isn't about the dogs' behaviour - it's about participatory design. By observing how the dogs react to the harness, the technology, and other factors, their feedback will be incorporated into future phases. This phase is still in pilot stage.

\subsection{Future Phases}

The next phases will involve similar methodology, and any technology would build on lessons learned from previous phases. One major change would be that I plan to introduce some sort of feedback for the dog - an example being perhaps when the owner is 10 minutes away, I would alert the dog. Depending on the feedback from the dogs, the technology might change from a smartphone to another piece of technology or the purpose might change in scope slightly.

Giving the dog information about the human is a reversal of much of the current pet-centric technology that will alert the human about the dog's heart rate, exercise, location, among other things. Dog-centred technology would help refocus $\mathrm{ACl}$ to think about the dog's needs, not just the human's needs. 


\subsection{Expected Contributions}

By incorporating topical $\mathrm{HCl}$ concerns of the politics of participatory design for marginalized populations into $\mathrm{ACl}, \mathrm{I}$ aim to contribute to the field of $\mathrm{ACl}$ by adding new dialogues into the community. Hopefully by the end of my research, I will have created technologies that designed to give humans/dogs more understanding of one another and created an ethical $\mathrm{ACl}$ framework demanding that welfare and well-being of animals be put first when working with animals. Additionally, my work will produce datasets/findings detailing dogs' understanding of humans and the environment around them.

\section{REFERENCES}

Bannon, L., Bardzell, J., and Bødker, S. (2018). Reimagining participatory design. Interactions, 26(1), 26-32.

Hall, L., McDonald, S. and Young, S., 2018, July. Barking up the wrong tree: a qualitative study of the potential for dog-owner technology. In British $\mathrm{HCl}$ Conference. ACM.

Seven years after the manifesto: Literature review and research directions for technologies in animal computer interaction. Multimodal Technologies and Interaction, 2(2), p.30.

Jackson, M.M., Zeagler, C., Valentin, G., Martin, A.,Martin, V., Delawalla, A., Blount, W., Eiring, S.,Hollis, R., Kshirsagar, Y. and Starner, T., 2013, September. FIDO-facilitating interactions for dogs with occupations: wearable dog- activated interfaces. In Proceedings of the 2013 international symposium on wearable computers (pp. 81-88).

Lawson, S., Kirman, B., Linehan, C., Feltwell, T. and Hopkins, L., 2015, April. Problematising upstream technology through speculative design: the case of quantified cats and dogs. In Proceedings of the33rd Annual ACM Conference on Human Factors in Computing Systems (pp. 2663-2672).

Mancini, C., 2011. Animal-computer interaction: a manifesto. Interactions, 18(4), pp.69-73.

Mancini, C., Lawson, S. and Juhlin O., 2017. Animal-Computer Interaction: The emergence of a discipline.

Neuhauser, L., Rothschild, B., Graham, C., Ivey, S.L. and Konishi, S., 2009. Participatory design of mass health communication in three languages for seniors and people with disabilities on Medicaid. American Journal of Public Health, 99(12), pp.2188-2195.

Paasovaara, S., Paldanius, M.,Saarinen, P., Häkkilä, J. and Väänänen-Vainio-Mattila, K., 2011, August. The secret life of my dog: design and evaluation of paw tracker concept. In Proceedings of the 13th International Conference on Human Computer Interaction with Mobile Devices and Services (pp.231-240).

Sheldrake, R., 2011. Dogs that know when their owners are coming home: And other unexplained powers of animals. Broadway Books 